\title{
REPRESENTAÇÕES SOCIAIS DA ÁGUA EM SANTA CATARINA
}

\author{
Gislei Mocelin Polli \\ Ariane Kuhnen" \\ Eliza Gonçalves de Azevedo" \\ Jamile Fantin ${ }^{\text {II }}$ \\ Roberta Ferreira Gasparino da Silva ${ }^{\infty}$
}

\begin{abstract}
RESUMO. Preocupações ambientais, entre elas problemas relacionados à água, estão cada vez mais presentes na sociedade contemporânea. Nesta pesquisa buscou-se conhecer as representações sociais da água em comunidades rurais de Santa Catarina. Este é um dos subprojetos do programa Tecnologias Sociais para Gestão da Água, patrocinado pela Petrobrás Ambiental. Para este estudo houve aplicação de instrumento de evocações livres, tendo como termo indutor "Água". As respostas foram tratadas pelos programas Evoc e Similitude 2000 e analisadas a partir da teoria do núcleo central. Os resultados indicam que a água é compreendida como essencial à vida, ligada à saúde e de necessária preservação. A sustentabilidade também é suscitada, pois a água é considerada essencial à sobrevivência. Seu uso em atividades cotidianas também foi considerado. Elementos como poluição, economia e escassez indicam preocupação com o que vem acontecendo em relação ao recurso e com a necessidade de preservá-lo.
\end{abstract}

Palavras-chave: psicologia ambiental, evocações livres, representação social..

\section{SOCIAL REPRESENTATION OF WATER IN SANTA CATARINA STATE}

\begin{abstract}
Environmental concerns, especially the ones related to the water, are each time more common in the society. In this research the goal was to understand the social representations of water in rural communities of Santa Catarina. This is one of the Program Social Technologies for Management of the Water's subprojects, sponsored for Environmental Petrobras. For this study it was applied an instrument of free evocations, with an inductive term "Water". The answers were treated by the programs Evoc and Similitude 2000, and analyzed through the theory of the central nucleus. The results indicate that the water is understood as essential to the life, related the health and it needs to be preserved. The sustainability also is remembered, therefore the water is considered essential to the survival. The use of the resource in daily activities was also considered. Elements as pollution, economy and scarcity indicate concern with what is happening to the resource and the necessities to preserve it.
\end{abstract}

Key words: Environmental psychology, free evocation, social representation.

\section{REPRESENTACIONES SOCIALES DEL AGUA EN SANTA CATARINA}

RESUMEN. Preocupaciones ambientales, entre ellos problemas relacionados al agua, están cada vez más presentes en la sociedad. En esta investigación se buscó conocer las representaciones sociales del agua en comunidades rurales de Santa Catarina. Este es uno de los proyectos subordinados al Programa: Tecnologías Sociales para la Gestión del Agua, patrocinado por la Petrobras Ambiental. Para este estudio fue aplicado un instrumento de evocación libre, teniendo como término inductor "Agua". Las respuestas fueron procesadas por los programas Evoc y Similitude 2000, y analisadas a partir de la teoría del núcleo central. Los resultados indican que el agua es entendida como escencial para la vida, ligada a la salud, y necesita ser preservada. La sustentabilidad también es considerada, pues el agua es considerada esencial para la sobrevivencia. El uso del recurso en actividades cotidianas también fue considerado. Elementos como polución, economía y escasez indican preocupación con lo que viene sucediendo con el recurso y a las necesidades de preservarlo.

Palabras-clave: Psicología ambiental, evocación libre, representación social..

* Psicóloga, Mestrado em Psicologia. Doutoranda pelo Programa de Pós-Graduação em Psicologia da UFSC..

\# Universidade Federal de Santa Catarina - UFSC, Departamento de Psicologia, Coordenadora do Laboratório de Psicologia Ambiental. Psicóloga, mestre em Sociologia Política e doutora em Ciências Humanas..

II Graduanda do Curso de Psicologia. Universidade Federal de Santa Catarina.

æ Psicóloga, Universidade Federal de Santa Catarina. 
Alimento e água sempre foram fundamentais para sobrevivência dos seres vivos, mas a perspectiva mudou quando o homem começou a se dar conta de que a forma como estes recursos vêm sendo utilizados tem causado sua degradação e rápida destruição, colocando em risco a própria existência da humanidade. Segundo informações da Organização das Nações Unidas (ONU), no último século o uso da água aumentou duas vezes mais do que a taxa de crescimento populacional e quase metade das áreas cobertas com água doce no planeta se perdeu.

Em face da amplitude dos problemas relacionados à questão da água, tem sido identificada a necessidade de mudanças, fazendo-se urgente uma reformulação na relação entre as pessoas e esse bem. A Conferência das Nações Unidas sobre Meio Ambiente e Desenvolvimento, realizada na cidade do Rio de Janeiro (Rio-92), é considerada um marco no tocante à preservação desse bem, tendo fortalecido os conclaves específicos sobre hidrologia em níveis nacionais e mundiais, o que impulsionou a promoção (ou aprimoramento) de leis específicas para águas em diversos países e consolidou o mais completo documento de recomendações sobre os recursos hídricos: a denominada Agenda 21. No Brasil, várias medidas tomadas pelo Governo Federal e alguns governos estaduais na década de 1990 parecem ter-se baseado nas recomendações da Rio-92, sendo considerado o país da América Latina com maiores avanços nesta área (Berbet, 2003; Fernandes, 2002; FUNASA, 2006).

Em 1997, a Lei n.9433, baseada em experiências existentes no próprio país e no modelo francês, criou o Sistema Nacional de Gerenciamento de Recursos Hídricos (SNGRH) e instituiu a Política Nacional dos Recursos Hídricos (PNRH), esta ultima com os objetivos de assegurar a sustentabilidade do recurso hídrico para as gerações futuras e atuais, garantir a qualidade da água e propor um uso racional do recurso com vistas ao desenvolvimento sustentável. Tais medidas representam um grande avanço na legislação, visto que até a década de 70 a questão da água no Brasil era pautada apenas nas necessidades dos usuários deste recurso ou nas políticas referentes às secas e inundações. A Lei n.9433/97 avança também ao consolidar a bacia hidrográfica como unidade territorial para implementação da PNRH e a atuação do SNGRH e estabelecer que a gestão dos recursos hídricos deve ser descentralizada e contar com a participação do poder público, dos usuários, e da comunidade (Fernandes, 2002).

Os comitês de bacias hidrográficas (CBHs) são a base do sistema de gerenciamento, constituindo-se num sistema de órgãos colegiados inteiramente novos na realidade institucional brasileira. São formados por representantes dos poderes públicos, dos usuários e das organizações civis voltadas às recuperação e conservação do meio ambiente. Devido às suas atribuições normativas, consultivas e deliberativas, estes comitês são também chamados de "parlamentos das águas", atuando como fóruns de decisão no âmbito de cada bacia. Entre as atribuições dos CBHs destacam-se: a promoção do debate das questões relacionadas aos recursos hídricos da bacia; a articulação das entidades que trabalham com esta questão; a arbitragem dos conflitos relacionados aos recursos hídricos; a aprovação e acompanhamento da execução dos planos de recursos hídricos; o estabelecimento de mecanismos de cobrança pelo uso de recursos hídricos e sugestão dos valores a serem cobrados; definição dos critérios para implementação das obras de uso múltiplo, de interesse comum ou coletivo (Berbet, 2003; Agência nacional das águas, 2008). Não obstante, enquanto surgem vários focos de implementação de comitês, há grande dificuldade em fazer com que a população participe de forma efetiva do processo decisório.

É nessa perspectiva que se insere o projeto Tecnologias Sociais para Gestão da Água (TSGAs), resultante de uma parceria entre a Universidade Federal de Santa Catarina (UFSC), a Empresa Brasileira de Pesquisa Agropecuária (Embrapa) e a Empresa de Pesquisa Agropecuária e Extensão Rural de Santa Catarina (EPAGRI), com financiamento do Programa Petrobrás Ambiental, que tem por objetivo aumentar a capacidade de gestão local da água mediante a implementação de tecnologias sociais em algumas cidades do Estado de Santa Catarina. Conhecer os pensamentos, representações, percepções e atitudes de lideranças locais das comunidades envolvidas com o projeto permite trabalhar educação ambiental a partir da perspectiva da população local. Esse artigo apresenta informações coletadas sobre a representação social do recurso água em lideranças das comunidades locais.

\section{REVISÃO TEÓRICA}

Alguns estudos em psicologia ambiental voltados à compreensão do comportamento de conservação do ambiente entendem que existe uma relação complexa entre o engajamento individual em ações de cuidado e a participação em organizações sociais dedicadas ao cuidado dos recursos, como é o caso dos CBHs. Por exemplo, alguns autores se dedicam a compreender os determinantes da preservação do recurso água (Aguayo, Herrera \& Palos, 
2004; Corral-Verdugo, 2003; Corral-Verdugo \& Pinhiero, 2006), outros procuram entender a forma como as pessoas percebem o ambiente e com ele se relacionam, buscando construir formas explicativas ou auxílio teórico para entender o comportamento. A teoria das representações sociais tem sido utilizada como um modelo teórico possível na busca da compreensão dessas relações (Andrade Junior, Souza \& Brochier, 2004; Castro, 2003; Félonneau, 2003; Jodelet, 1989; Kuhnen, 1995; Kuhnen, 2002; Peluso, 2003; Reigota, 2004).

No campo ambiental a teoria das representações sociais tem um valor incontestável na busca da compreensão das dinâmicas sociais. Nesta perspectiva se insere a maior parte dos trabalhos sobre o modo como o sujeito percebe o ambiente, relacionando-o com sua história, suas experiências, seus afetos, ou mesmo com sua competência ambiental. A representação social do ambiente traduz o modo como se dá a relação do sujeito com seu ambiente (Félonneau, 2003, Jodelet, 1989).

A representação social é uma atividade na qual ocorre uma representação mental e social da realidade que permite às pessoas ou grupos ajustar-se ao ambiente e orientar sua conduta (Jodelet, 1989). O estudo da representação social permite compreender como as pessoas entendem o seu mundo, desde o ambiente e as relações sociais até aspectos relativos à sua própria identidade. Ele é de grande relevância no estudo da relação pessoa-ambiente, principalmente se tivermos a mediação social como parte significativa nesta relação.

Jodelet (2001) caracteriza a representação social como "uma forma de conhecimento socialmente elaborada e partilhada, com um objetivo prático, e que contribui para a construção de uma realidade comum a um conjunto social" (p.22). Apesar de se manifestarem como elementos cognitivos, as representações sociais não se limitam a esta característica, pois são elaboradas e compartilhadas socialmente, contribuindo desta forma para a construção de uma realidade comum, que possibilita a comunicação (Jodelet, 1993). As representações sociais são ativadas em ações na vida social, e seus elementos constituem um saber que diz algo sobre a realidade, portanto se caracterizam como uma forma de conhecimento elaborado e partilhado socialmente que resulta em uma realidade comum a um grupo social e em um saber do senso comum que, apesar de diferenciado do conhecimento científico, pode ser influenciado por este (Jodelet, 2001).

Como forma de tornar o estudo das representações sociais mais heurístico para a prática social e para a pesquisa, a teoria do núcleo central se mostra de grande valia. A teoria das representações sociais pode ser considerada uma grande teoria, em relação à qual a teoria do núcleo central constitui uma abordagem complementar que proporciona descrições mais detalhadas e explicações sobre o funcionamento de certas estruturas de forma compatível com a teoria geral (Sá, 1996). Abric (1994) assim se refere à organização da representação social:
A organização de uma representação apresenta uma característica particular: não apenas os elementos da representação são hierarquizados, mas além disso toda representação é organizada em torno de um núcleo central, constituído de um ou de alguns elementos que dão à representação seu significado (p. 62).

A teoria do núcleo central permite compreender a estrutura da representação social através do estabelecimento de zonas centrais e periféricas de tal representação. Os elementos centrais se referem à memória coletiva, à história do grupo, ao sistema de valores e ao envolvimento na situação social, constituindo-se como uma base comum e consensual de uma representação; os elementos periféricos, por suja vez, referem-se a zonas potenciais de mudança das representações ou elementos, ainda que sem relevância significativa para o grupo estudado (Abric, 1994).

Com base na abordagem estrutural das representações sociais, que fornece conhecimento teórico e arsenal metodológico para a obtenção de indicações sobre o modo de pensar a água, buscou-se compreender a relação estabelecida pela população estudada com esse recurso natural, bem como sua influência sobre os valores, atitudes, opiniões e comportamentos.

\section{MÉTODO}

\section{Participantes}

Responderam à pesquisa 104 pessoas, das quais $74(71,2 \%)$ eram do sexo masculino e $30(28,8 \%)$ do sexo feminino, com idades entre 21 e 70 anos e média etária de 43 anos. O grau de instrução varia de ensino fundamental incompleto (15\% dos participantes) a superior completo (59\%).

O grupo é composto de educadores, lideranças econômicas, sociais e religiosas, jornalistas, agricultores e membros da comunidade, os quais estão sendo formados pelo projeto TSGA para atuarem como monitores em seus municípios. Para tanto, participam das chamadas oficinas de capacitação da comunidade para o uso das tecnologias sociais, ministradas nas cidades de Concórdia, Urubici, Turvo e Orleans, municípios de Santa Catarina.

\section{Instrumento}

Com o objetivo de conhecer as representações sociais dos participantes a respeito da água e suas 
variações, foi elaborado um questionário contendo, além de questões para identificação do perfil socioeconômico, cinco questões de evocações livres: 1) Escreva cinco palavras ou expressões que lhe vêm imediatamente à cabeça ao se falar em água; 2) $O$ que você relaciona a água de qualidade? Escreva cinco palavras ou expressões; 3) Água poluída faz você pensar em quê? Indique cinco palavras ou expressões; 4) Escreva cinco palavras ou expressões que você relaciona à preservação da água; 5) Escreva cinco palavras ou expressões que você relaciona ao uso e à exploração da água. Ao final de cada questão, pediu-se que os participantes assinalassem um $\mathrm{X}$ nas duas palavras evocadas que considerassem as mais importantes. Para este artigo serão apresentadas as palavras referentes à questão um, enquanto as demais estão sendo analisadas.

A técnica de evocações livres é de grande valia no estudo das representações sociais, permitindo conhecer sua estrutura e organização mediante análise baseada na teoria do núcleo central. Tal técnica consiste na apresentação de termos indutores aos respondentes, os quais devem escrever palavras ou expressões que lhes venham à mente a partir de tais termos (Oliveira, 2005).

\section{Procedimento}

A partir da elaboração do questionário, realizouse um estudo-piloto com estudantes universitários, a fím de verificar se a organização e a semântica do instrumento estavam adequadas ao objetivo proposto. Após esse estudo, organizou-se a versão final do questionário, que possibilitou a coleta de dados.

A aplicação foi realizada durante os intervalos das primeiras oficinas de capacitação da comunidade para o uso das tecnologias sociais, ocorridas, respectivamente, nas cidades de Concórdia, Urubici, Turvo e Orleans. As instruções eram fornecidas coletivamente, em grupos de aproximadamente cinco pessoas. Posteriormente, viu-se a necessidade de aperfeiçoar a técnica, passando-se a instruir os participantes individualmente, em vista da dificuldade das pessoas com menor grau de instrução em compreender as instruções dadas coletivamente.

\section{Análise de dados}

A análise dos dados obtidos através de associação livre com a utilização da palavra "água" como termo indutor foi lexicográfica, ou seja, foram consideradas a frequência e a ordem de evocação das palavras. Este conhecimento permite determinar a estrutura da representação. Para o tratamento dos dados foram utilizados o software Evocation 2000 - Ensemble de programmes permettant l'analyse des evocations (Vèrges, 1999) e Similitude 2000 - Analyse de similitude de questionnarires et de données numériques (Vèrges, 1997). As palavras foram agrupadas em categorias semanticamente próximas e tratadas pelos programas.

O software Evocation 2000 fornece a frequência simples das palavras evocadas e a ordem de evocação média de cada uma delas, resultando em sua distribuição em quatro quadrantes, através dos quais "se discriminam o núcleo central, os elementos intermediários (ou $1^{\mathrm{a}}$ periferia e elementos de contraste) e os elementos periféricos da representação (ou 2 $2^{\mathrm{a}}$ periferia)" (Moreira, 2005, p. 581), de forma a determinar as palavras possivelmente pertencentes ao núcleo central da representação. Durante a sua execução, definiu-se 3 como frequência mínima, que corresponde a $76 \%$ das palavras evocadas, o que significa dizer que foram analisadas as palavras evocadas três ou mais vezes na utilização do software. Uma análise confirmatória, obtida por meio da indicação feita pelos respondentes das duas palavras que consideraram mais importantes entre as cinco apontadas, pôde confirmar os dados. As palavras que fazem parte do núcleo central, de acordo com o software, e que foram marcadas como mais importantes em pelo menos $50 \%$ das vezes em que foram citadas, foram confirmadas como parte do núcleo central.

O software Similitude 2000 permite uma visualização das conexões existentes entre os elementos presentes no núcleo central da representação social da água. Essa técnica se fundamenta na teoria dos grafos, utilizando a relação de ligação pareada de variáveis (Camargo, Barbará \& Bertoldo, 2007).

\section{RESULTADOS E DISCUSSÃO}

Foram feitas 514 evocações com 153 palavras diferentes. Considerando-se a proximidade semântica, foram criadas 23 categorias, das quais fizeram parte $76 \%$ das palavras evocadas. A média de evocações por categoria semântica foi de 2,26, tendo sido essas evocações lembradas, em média, na terceira posição (ordem média de evocação = 2,98).

Os resultados obtidos estão expressos pela distribuição nos quadrantes (ver quadro 1), em que o eixo horizontal divide as palavras por frequência de evocação, estando acima da linha horizontal as palavras que foram evocadas 7 vezes ou mais, e abaixo, as palavras evocadas entre 4 e 6 vezes. $O$ eixo vertical, por sua vez, divide as palavras de acordo com 
a ordem de evocação em que apareceram, encontrando-se à esquerda do eixo as palavras mais prontamente evocadas (evocação na primeira ou segunda posição), e à direita do eixo, as palavras menos prontamente evocadas (após a terceira posição).

Destarte o quadrante superior esquerdo apresenta as palavras com maior frequência de evocação e evocadas mais prontamente, de forma a compor as palavras que possivelmente fazem parte do núcleo central da representação. Os quadrantes superior direito e inferior esquerdo compõem a primeira periferia da representação, formada pelos elementos que estão hierarquicamente mais próximos do núcleo central e representam zonas de possíveis modificações. As palavras alocadas no quadrante inferior direito pertencem ao sistema periférico da representação e se encontram mais afastadas do núcleo central.

Quadro 1. Quadrante das Palavras Evocadas a Partir do Termo Indutor Água, de Acordo com a Ordem de Evocação e a Frequiência

\begin{tabular}{|c|c|c|c|c|c|}
\hline \multicolumn{3}{|l|}{$\mathrm{OME}^{* * *} \leq 2$} & \multicolumn{3}{|l|}{$O M E>3$} \\
\hline $\begin{array}{l}\text { Higiene } \\
\text { Necessidade } \\
\text { Poluição } \\
\text { Potabilidade } \\
\text { *Preservação } \\
\text { Pureza } \\
\text { Qualidade } \\
\text { *Saúde } \\
\text { Sede } \\
\text { *Sobrevivência } \\
\text { *Vida } \\
\text { F } \geq 7\end{array}$ & $\begin{array}{l}10 \\
8 \\
16 \\
7 \\
20 \\
14 \\
12 \\
26 \\
9 \\
9 \\
71\end{array}$ & $\begin{array}{l}2,60 \\
2,62 \\
2,56 \\
1,71 \\
2,65 \\
2,71 \\
2,16 \\
2,27 \\
2,79 \\
2,55 \\
1,66\end{array}$ & $\begin{array}{l}\text { Alimento } \\
\text { Economia } \\
\text { Escassez } \\
\text { *Natureza } \\
\text { *Sustentabilidad }\end{array}$ & $\begin{array}{l}9 \\
8 \\
11 \\
10 \\
10\end{array}$ & $\begin{array}{l}3,00 \\
4,37 \\
3,27 \\
3,30 \\
3,14\end{array}$ \\
\hline $\begin{array}{l}\mathrm{F}<7 \\
\text { Indispensável } \\
\text { Limpa }\end{array}$ & $\begin{array}{l}5 \\
4\end{array}$ & $\begin{array}{l}1,80 \\
1,75\end{array}$ & $\begin{array}{l}\text { Beleza } \\
\text { Bem-comum } \\
\text { Bem-estar } \\
\text { Chuva } \\
\text { Cuidado } \\
\text { Fundamental } \\
\text { Futuro } \\
\text { Harmonia } \\
\text { Importante } \\
\text { Limpeza } \\
\text { Mau-uso } \\
\text { Meio-ambiente } \\
\text { Proteção } \\
\text { Rio } \\
\text { Riqueza } \\
\text { Valorizar }\end{array}$ & $\begin{array}{l}4 \\
6 \\
4 \\
6 \\
6 \\
5 \\
4 \\
4 \\
5 \\
4 \\
4 \\
5 \\
6 \\
5 \\
4 \\
4\end{array}$ & $\begin{array}{l}3,00 \\
4,00 \\
3,25 \\
3,33 \\
3,33 \\
3,40 \\
3,75 \\
3,25 \\
4,40 \\
3,25 \\
4,00 \\
3,40 \\
3,50 \\
3,00 \\
4,00 \\
4,00\end{array}$ \\
\hline
\end{tabular}

*elementos confirmados como pertencentes ao núcleo central

**Ordem média de evocação

A partir da análise lexicográfica, efetuada com o auxilio do software Evocation 2000, pôde-se constatar que a representação social da água do grupo estudado era, possivelmente, formada pelos seguintes elementos organizadores: higiene, necessidade, poluição, potabilidade, preservação, pureza, qualidade, saúde, sede, sobrevivência e vida.
A análise confirmatória das palavras pertencentes ao núcleo central, feita a partir das palavras que os respondentes consideraram como mais importantes, confirmou a centralidade de quatro das onze palavras do núcleo central (preservação, saúde, sobrevivência $e$ vida). Além dessas palavras, foi confirmada a centralidade de duas palavras, indicadas como provavelmente pertencentes à primeira periferia: natureza e sustentabilidade.

Este núcleo central evidencia a compreensão da água como um elemento essencial à vida, que é ligado à saúde e precisa ser preservado. A necessidade da sustentabilidade também é suscitada quando se pensa na água, pois ela é considerada como necessária à sobrevivência.

Os elementos periféricos higiene, necessidade, potabilidade, qualidade, sede, alimento e indispensável enfatizam a necessidades e o uso feito do recurso para atividades fundamentais na vida cotidiana. Elementos como poluição, economia e escassez indicam preocupação no tocante ao que vem acontecendo com o recurso e a necessidade de preservá-lo.

Ao analisar a evocação das palavras de acordo com o sexo do respondente (resguardando-se a proporção de 2,5 respondentes do sexo masculino para cada respondente do sexo feminino), verificou-se que alguns elementos do núcleo central foram mais lembrados pelos homens, como natureza, preservação e sustentabilidade, o que evidencia uma preocupação maior desses respondentes com os aspectos relacionados ao desenvolvimento econômico e com a manutenção dos aspectos naturais. Itens periféricos como economia, necessidade, poluição e pureza foram encontrados com maior frequência no discurso das mulheres, o que evidencia uma preocupação com a água em seu uso diário, ou seja, com suas características enquanto um bem necessário.

Ao estudar a conexidade dos elementos podemos visualizar a organização da representação. A conexidade é estabelecida a partir de um número mínimo de co-ocorrências em um grupo de evocações. A representação gráfica dos estudos de conexidade é chamada árvore máxima. Nos vértices encontramos as variáveis, e em suas ligações, a co-ocorrência entre os elementos. As categorias que se conectam ao final da aplicação de um filtro são as que apresentam um grau mais forte de conexão, e estão relacionadas ao número de pessoas que tratam tais elementos de maneira semelhante. Desta forma um elemento será tanto mais ligado a outro quanto mais permanecer em um conjunto de filtros mais elevados (Camargo, Barbará $\&$ Bertoldo, 2007). O primeiro filtro utilizado foi de 7 co-ocorrências (ver figura 1) 


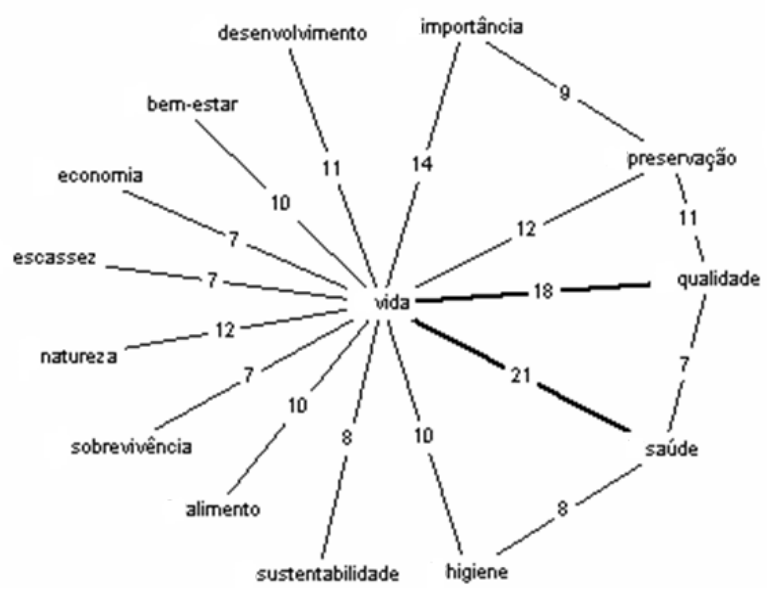

Figura 1. Árvore Máxima 7 Co-ocorrências

A palavra vida assume posição central, conectando-se com todos os elementos na árvore, o que evidencia seu papel organizador na representação social da água. Os elementos qualidade e saúde estão conectados mais fortemente com a palavra vida, e também mostram conexão entre si, embora mais fraca, o que indica que a qualidade da água está fortemente ligada ao caráter de vitalidade, asim como vida está ligada a saúde. $\mathrm{O}$ elemento preservação se liga com importância e qualidade, e o elemento saúde se liga com o elemento higiene. Os demais elementos não apresentam conexão entre si, sendo todos organizados ao redor do elemento vida.

Para conhecer os elementos mais fortemente ligados à palavra vida foi aplicado um filtro 12 (Figura 2)

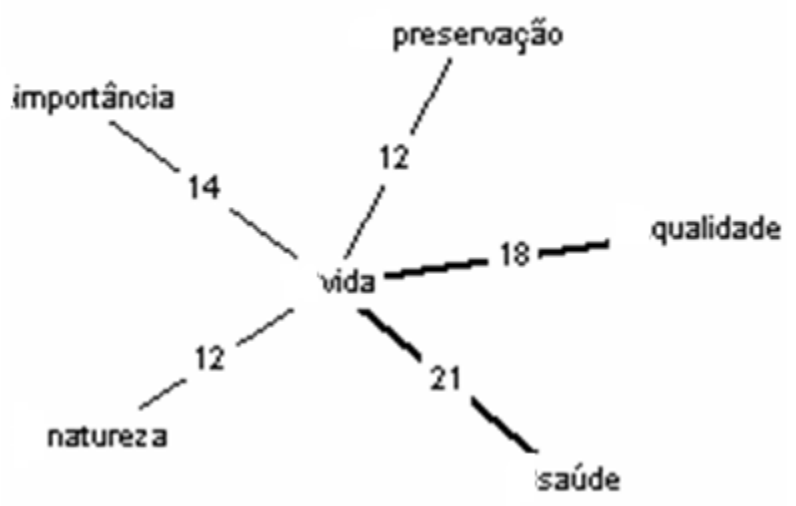

Figura 2. Árvore Máxima 12 Co-ocorrências

Com um nível de exigência mais alto (12 coocorrências), a ligação entre qualidade e saúde não se manteve, de modo que as palavras importância e qualidade, que fazem parte do sistema periférico, e as palavras preservação, saúde e natureza, parte do núcleo central, se mantiveram ligadas à palavra vida, que parece ser o elemento do núcleo central que exerce maior força organizadora na representação social da água.

Este estudo verificou que a representação social da água é formada pelos elementos centrais vida, preservação, saúde, sobrevivência, natureza e sustentabilidade. Considerando que o grupo estudado recebe informações sobre a água de modo semelhante ao da população em geral, podemos ter em conta que a expressão "água é vida" vem sendo dita pela mídia, pelos ambientalistas, pela educação ambiental e pelo próprio sistema educacional há muito tempo. A Campanha da Fraternidade da Igreja Católica, divulgada em âmbito internacional, utilizou o slogan "água, fonte de vida" no ano de 2004 (Campanha da fraternidade, 2004), e na escola é ensinado que o corpo humano se compõe $70 \%$ de água, de modo que não é surpresa o termo aparecer como elemento central nessa população, o que, aliás, seria esperado em relação a populações diferentes, visto que a expressão alcança abrangência internacional. A pesquisa realizada pelo Laboratório de Psicologia Ambiental da UFSC (FUNASA, 2006) encontrou o elemento vida como central na representação social do elemento água em uma população bastante distinta da população estudada neste trabalho.

O elemento saúde aparece com grande importância no núcleo central, fortemente ligado ao elemento vida e também ao elemento qualidade. $\mathrm{O}$ sistema educacional formal trabalha o conceito de saúde ligado a diversos aspectos, entre eles a qualidade da água, e também a mídia vem divulgando informações a esse respeito nas campanhas de preservação do recurso. Tais campanhas de preservação têm ocorrido com bastante frequência, e informações sobre a situação da água no Brasil e no mundo têm se tornado cada vez mais presentes nestas campanhas e nos jornais, sejam estes impressos ou televisivos, o que pode contribuir para que os termos preservação e sustentabilidade também façam parte do núcleo central da representação social da água no grupo estudado. O elemento sobrevivência tem significado muito próximo ao significado do elemento vida, no entanto parece demonstrar preocupação com o futuro da humanidade ou do planeta, considerando a manutenção da vida ao longo do tempo. A palavra natureza ,que também faz parte do núcleo central, demonstra uma possível influência que a educação formal tenha exercido na formação da representação social da água, visto que na escola nos são ensinadas as características da água enquanto elemento natural.

Abric (1998) discute o caráter consensual e ao mesmo tempo dotado de diferenças individuais de 
uma representação social, o que, de acordo com o autor, é compreensível a partir do conhecimento da estrutura da representação social. "A homogeneidade de uma população não é definida pelo consenso entre seus membros, mas sim pelo fato que sua representação se organiza em torno do mesmo núcleo central" (p. 34).

O núcleo central é composto por elementos ligados à memória coletiva e à história do grupo; é estável, coerente e rígido, resiste às mudanças e é pouco sensível ao contexto imediato. Por sua vez, o sistema periférico permite a integração de experiências e histórias individuais, é flexível e tolera contradições, está em constante evolução e é sensível ao contexto imediato (Abric, 1998). Deste modo, podemos entender que, no grupo em questão, as palavras vida, preservação, saúde, sobrevivência, natureza e sustentabilidade compõem um campo de homogeneidade, ou seja, constituem o centro da representação que é comum ao grupo estudado. Os elementos periféricos higiene, necessidade, poluição, potabilidade, pureza, qualidade, sede, alimento, economia, escassez, indispensável e limpa são flexíveis e possuem caráter individual, não sendo todas as palavras comuns ao grupo todo. Essas palavras assumem uma função de defesa do núcleo central, por seu caráter evolutivo, sofrem mudanças, novas interpretações e integração de novos elementos, de modo a preservar o núcleo central da representação.

\section{CONSIDERAÇÕES FINAIS}

A análise dos resultados a partir da teoria do núcleo central nos mostra que são mais comuns à população estudada características positivas da água, tendo sido enfatizada a prevenção de problemas relacionados ao recurso. Outros estudos são necessários para determinar se os resultados encontrados são particulares destes respondentes, por serem parte de um grupo reflexivo, de acordo com a classificação proposta por Wagner (1998), segundo a qual grupos reflexivos são formados por membros que reconhecem sua afiliação a um determinado grupo.

Conquanto a representação social encontrada seja resultante do envolvimento dos participantes com programas de educação ambiental e projetos sociais, e por esse motivo não possamos inferir que encontraríamos uma representação social da água semelhante em um grupo escolhido aleatoriamente, os dados encontrados apontam para a efetividade de programas voltados à preservação da água, e reforçam a importância de envolver a população em geral nos programas de preservação e na gestão participativa das águas.

Não obstante, é fato que campanhas de preservação enfatizaram, por um longo período (e ainda o fazem atualmente), a necessidade de ações preventivas em relação à água. Atualmente já se percebe a necessidade de medidas de correção, pois em muitos locais a água se encontra bastante poluída ou escassa, não sendo suficientes ações preventivas; porém tais ações corretivas não são incumbência direta da população, que é estimulada a continuar com o comportamento de preservação - fundamental para a manutenção ou a melhoria do recurso. Deste modo, elementos ligados à recuperação ou a preocupação com os problemas que já ocorrem, como poluição e escassez, fazem parte do sistema periférico da representação. Embora seja incumbência do sistema de governo a recuperação de rios e baías, é importante que a população tenha conhecimento sobre a realidade para exercer papel de coerção perante a administração pública, para que tais medidas sejam executadas de forma mais rápida e eficiente.

Atualmente itens relacionados a este tema se encontram no sistema periférico da representação, o que pode ser um indicativo de que caminham para o núcleo central, de modo a promover uma mudança na representação social da água, que, além de ser considerada elemento fundamental à vida, passaria a ser também tida como elemento a ser recuperado. $\mathrm{O}$ caminho começou a ser trilhado e é importante continuar chamando a atenção da população - seja isto feito através da mídia, da educação formal ou da educação ambiental - para a necessidade de, além de se preocupar com a preservação da água, preocupar-se também com a recuperação do recurso.

\section{REFERÊNCIAS}

Abric, J. C. (1994). Les représentations sociales: aspects théoriques. Dans J. C. Abric (Ed.), Pratiques sociales et représentations (1135). Paris, Presses Universitaires de France.

Abric, J. C. (1998). A Abordagem estrutural das representações sociais. Em A. S. P. Moreira \& D. C. de Oliveira (orgs.), Estudo interdisciplinares de representação social (27-38). Goiânia: AB.

Agência Nacional das Águas. (2008). Recuperado em 27 de março de $2008 \mathrm{em}$ http://www.mma.gov.br/port/srh/sistema/ana.html

Aguayo, J. M. B., Herrera, M. F. \& Palos, P. A. (2004). Predicción de la conservación de agua a partir de factores socio-cognitivos. Medio Ambiente Y Comportamiento Humano, 5(1-2), 53-70.

Andrade Junior, H., Souza, M. A. \& Brochier, J. I. (2004). Representação social da educação ambiental e da educação em saúde em universitários. Piscologia: Reflexão e Crítica, 17(1), 4350 . 
Berbet, C. O. (2003). O Desafio das Águas. In: R. M. Martins, \& N. Felicidade, (Org). Uso e gestão dos recursos hídricos no Brasil: desafios teóricos e político-institucionais (81-97). São Carlos: RiMa.

Camargo, B.V., Bárbara, A., \& Bertoldo, R. B. (2007). Concepção pragmática e científica dos adelescentes dobre a AIDS. Psicologia em Estudo, 12(2), 277-284.

Campanha da fraternidade (2004). Recuperado em 01 de maio 2008 em http://www.cf.org.br/cf2004/concurso.php

Castro, P. (2003). Pensar a natureza e o ambiente - alguns contributos a partir da teoria das representações sociais. Estudos de Psicologia, 8(2), 263-271.

Corral-Verdugo, V. (2003). Determinantes Psicológicos e situacionais do comportamento de conservação de água: um modelo estrutural. Estudos de Psicologia, 8(2), 245-252.

Corral-Verdugo, V. \& Pinheiro, J. Q. (2006). Sustainability, future orientation and water conservation. Revue européene de psychologie appliqué, 56, 191-198.

Félonneau, M. L. (2003). Les représentations sociales dans le cham de l'environnement. In: G. Moser \& K. Weiss (orgs.), Espaces de vie: Aspects de la relation homme-environnement (p. 145-176) Paris: Armand Colin

Fernandes. A. C. C. (2002). Os Comitês de Bacias Hidrográficas e suas implicações para o gerenciamento dos recursos hídricos. Monografia Não-Publicada, Curso de Bacharelado em Economia, Universidade Federal do Rio de Janeiro, Rio de Janeiro.

FUNASA (2006). Relatório de Pesquisa: Representações e praticas sociais ligadas à água. UFSC. Funasa.

Jodelet, D. (1989). Las Representaciones Sociales del médio ambiente. En L. Íñiguez, E. Pol (Comp.), Cognición, representación y apropriación del espacio (29-42). Barcelona: Universitat de Barcelona.

Jodelet, D. (1993). O conceito de representação social na abordagem Psicossocial. Cad. Saúde Públ., 9(3), 300-308.

Jodelet, D. (2001). Representações sociais: um domínio em espanção. Em D. Jodelet (org.), As representaçõe sociais (p. 17-44). Rio de Janeiro: EDUERJ.
Kuhnen, A. (1995). Reciclando o cotidiano: representações sociais do lixo. Florianópolis: Letras Contemporâneas.

Kuhnen, A. (2002). Lagoa da conceição: meio ambiente e modos de vida em transformação. Florianópolis: Cidade Futura.

Lei n.9.433, de 8 de janeiro de 1997. (1997). Dispõe sobre a instituição da Política Nacional de Recursos Hídricos, cria o Sistema Nacional de Gerenciamento de Recursos Hídricos, e dá outras providências. Brasília, DF. Recuperado em 08 de abril de $2008 \mathrm{em} \mathrm{http://www.lei.adv.br/9433-97.htm}$

Oliveira, D. C. et al. (2005). Análise das evocações livres: uma técnica de análise estrutural das representações sociais. In: A. S. P. Moreira (Org.), Perpectivas teórico-metodológicas em representações sociais. Ed. Universitária UFPB, João Pessoa PB.

Peluso, M. L. (2003). O potencial das representações sociais para a compreensao interdisciplinar da realidade: Geografia e Psicologia Ambiental. Estudos de Psicologia, 8(2), 321-327.

Sá, P. C. (1996) Núcleo Central das Representações Sociais. Ed.Vozes, Petrópolis RJ.

Reigota, M. (2004). Meio ambiente e representação social. São Paulo: Cortez.

TSGA (2007). Projeto de Pesquisa: Tecnologia Sociais para Gestão da Água. UFSC. Programa Petrobras Ambiental.

Vèrges, P. (1997). SIMI - analyse de similitude de questionnaires et de donnees numeriques: manuel version 1.2. Aix-emProvence:LAMES.

Vèrges, P. (1999). Essemble de programmes permettant l'analyse des evocarions: manuel version 2. Aix-em-Provence:LAMES.

Wagner, W. (1998). Sócio-gênese e características das representações sociais. In: A. S. P. Moreira \& D. C. Oliveira (orgs.), Estudos interdisciplinares de representação social (3-25). Goiânia: AB.

Endereço para correspondência : $\quad$ Gislei Mocelin Polli. Rua Doutor Abel Capela, 995, ap. 101, B1. 03, Coqueiros, CEP 88080251, Florianópolis-SC, Brasil. E-mail: gismocelin@gmail.com 